\title{
Kavanaugh vs Ford: Gender Politics in the Hearing of Sexual Assault Allegation Case
}

\author{
Triana Budi Utami ${ }^{1}$, Muhammad Fuad ${ }^{2}$ \\ \{trianautamii@gmail.com ${ }^{1}$, faseha.fuad994@gmail.com² \\ ${ }^{1,2}$ American Studies, School of Strategic and Global, Universitas Indonesia
}

\begin{abstract}
Sexual assault allegation against Brett Kavanaugh by Christine Blasey Ford has become the United States' important issue in September 2018. The complaint arose coincided with Kavanaugh's nomination as one of the United States Supreme Court Justice, and it sparked debate between the left and right-wing political parties. Apart from the many support, Ford gets from the feminist and liberal groups. The allegation was eventually dismissed by the White House due to Kavanaugh's confirmation to the Supreme Court Justice on October 8, 2018. This paper will analyze both Kavanaugh and Ford's politic gender strategy in the allegation hearing on September 26, 2018. This paper uses Sexual Politic by Kate Millet as a theoretical framework and thematic analysis as the research method. The result shows that either Kavanaugh or Ford experience the same disadvantages, and none of them experience any victories by this case.
\end{abstract}

Keywords: Sexual assault, Christine Ford, Brett Kavanaugh, Sexual Politics, gender politics

\section{Introduction}

Peer-to-peer sexual assault is a significant problem in schools and universities in the United States. Nearly two-thirds of students experience various types of sexual harassment in their lives. However, less than 10 percent of these students tell colleges or universities about their experiences. Only a small number of them officially report it to the authorities (Hill \& Silva, 2005, p.2). Apart from universities, sexual harassment also often occurs at the junior and senior high school levels. Sexual harassment in this level of education can occur between teacher and student, or student and student. Sexual harassment in schools is almost three times more likely to be done by students than teachers (Conroy, 2013, p.342). Middle and high school is a period where students step into puberty, where they have a natural urge and desire to explore their sexuality. However, most of teenagers seldom have a good understanding of the consequences of sexual acts. Also, wrong associations and social pressure also become the factors of peer-topeer sexual harassment. Adolescents often try to tolerate harassment to maintain social acceptance within their peer group (Conroy, 2013, p.341). The sexual harassment toleration among adolescent has normalized sexual harassment itself. Example, Long (2017) explains that there is a tradition called "Slapping Ass Friday" at an elementary school in California. In this kind of culture, the boys were encouraged to slap or grab their female classmates' buttocks. Besides justifying that sexual harassment is normal, the example above shows that the culture also justifies boys or males are allowed to be aggressive towards girls or females. The acceptance of such behavior is the result of gender stereotype internalization in the society. In 
gender stereotype, men are expected to be aggressive and dominant; meanwhile women are expected to be more submissive.

One of the alleged victims of peer-to-peer sexual assault is Christine Blasey Ford. Ford is a professor at the University of Palo Alto, California who allegedly harassed by Brett Kavanaugh in 1982 when both of them were still attending school. Ford contacted Congresswomen Anna Eshoo and The Washington Post regarding the incident that occurred 36 years ago, 11 days after Brett Kavanaugh's nomination as one of the United States Supreme Court Justices (Brown, 2018). Furthermore, Brown (2018) explains that through congresswomen Eshoo, Ford's sent a letter regarding the incident to Senator Diane Feinstein from California. After recounting the incident she experienced, Ford firmly requested that her identity be kept confidential. However, eventually, Ford's identity was revealed to the public and the case became the national spotlight in the United States. Based on Ford's confession in a hearing on September 26, 2018, the incident occurred at a party held at one of their friend's houses. Ford stated that Kavanaugh was under the influence of alcohol pulled her into a room and tried to rape her. Although the rape did not occur (there was no penetration), the incident left a deep trauma on Ford. This allegations sparks controversy because it arose coincided with Kavanaugh's Supreme Court Justice nomination. The majority of conservatives who are partisans of the Republican Party consider the allegation as Democratic Party effort to overthrow Brett Kavanaugh from the nomination. The evidence owned by Ford on the complaint is quite weak. The proofs are circumstantial or indirect evidence. Indirect evidence is evidence that has no direct connection to the accused, such as fingerprints or DNA. One of the most substantial proof that Ford has is a record from his therapist in 2012 - 2013 when she was talking about the assault (Zhou, 2018). The record from her therapy session also cannot be used as strong evidence because Ford did not mention Kavanaugh's name as the culprit in that therapy. In contrast the majority of liberal and feminist groups support Ford. Most of Ford's supporters support her on Twitter with hashtag Me Too. Moreover, the founder of the Me Too movement, Tarana Burke, made an open letter to Ford as a form of support and gratitude. Burke said that Ford's testimony is an example of an act of courage from the oppressed (Fortin, 2018).

Despite all the criticism and controversy, president Trump gives his full support to Kavanaugh. DiSanto (2018) revealed that the reason Trump nominated and supported Kavanaugh he has an extensive legal and judicial experience. Trump's support indeed sparks more controversy and antipathy towards Kavanaugh. More than 2400 law professors in the United States signed a petition not to confirm Kavanaugh as Supreme Court Justice, and it was published in The New York Times opinion column on October 4, 2018. Besides all of the protests against Kavanaugh, he was eventually confirmed as one of the Supreme Court justice of the United States on October 5, 2018. The decision was predictable due to Kavanaugh's political support as a member of the Republican Party, which has more power in Trump's administration. In accordance with Kavanaugh's confirmation as the United States Supreme Court Justice, all charges and complaints against him cannot be proceeded or must be stopped. Chief Judge Tymkovich stated that lower or general court judges do not have the authority to investigate or discipline Supreme Court Justices like Kavanaugh's (Totenberg, 2018). The dismissal of all the complaints and allegations towards Kavanaugh due to his Supreme Court Justice confirmation shows his dominance in the US political world

This paper will analyze how Kavanaugh and Ford strategize their gender politics in their hearing opening statements. The dismissal of all the complaints and allegations itself is explicit prove that Kavanaugh has more power than Ford politically. Both Ford and Kavanaugh have their patterns and ways of defending themselves in the hearing of the allegations which took place on September 26, 2018, ago. Both Kavanaugh and Ford have their ways to politicize their 
gender situation either as the accused or accuser for their benefits (to defend or to accuse one another). However, this paper will also show that no matter how strong the support Ford's get from the majority, the lack of evidence will bring her nowhere in this case. Generally, in a democratic country, the power of the majority can change almost every consensus that exists in a society. On the other hand, is criminal case like rape or rape attempt, forensic evidence is more critical than support and opinion from the majority.

\section{Theoretical Framework and Method}

The theory used in this research is the sexual politics theory by Kate Millet. Gender is characteristics a person have as the results of social construction, while sex refers to biological differences between male and female such as genitalia (Heig, 2004). There are expectations of attitudes that a person should have based on their sex. For example, men are expected to have courageous and aggressive dispositions, while women are expected to be gentle and submissive. The term "politics" used by Millet (2000) refers to structured power relations in which another group controls one group. "Groups" in Millet's theory are divided by gender or sex (male and female). Millet's Sexual Politics theory initially used to criticize pornographic novels in the 1950s - 1960s that tended to objectify women. Jeffreys (2010) argues that Millet views sexual practices as constructed by patriarchal power relations that reflect male domination. The portrayal of male dominance in Millet's sexual politics can be found from the use of words in the novel that tend to degrade women, as Jeffrey (2010) explains:

"Millett's analysis shows that the word 'fuck' is exciting to men because it is freighted with meanings of male power and the degradation of women. It is not an innocent word denoting sex, as can be adduced from the cruel excitement with which these novelists used the term. The word 'cunt' too, as used by such men, is not neutral, but a word that signals their contempt for women's genitals. The use of these words has often been confused with sexual freedom on the understanding that they are simply descriptive. Their use in the novels Millett analyses makes it very clear that they bear hostile masculine ideas about sex and women, and could not be easily taken up as women's language” (p.79).

This opinion assumes that vulgar expressions that use the body parts of women are one example of the dominance or power of men over women. Although vulgar expressions related to female anatomy are varied, vulgar expressions that also use male anatomy such as "dick" (penis), which means "rascal" or a bad person, used in verbal expression. It also shows that the expression implies an evil person is always associated with men. Therefore, basically, at present time, both men and women have the same opportunities and levels of expression. Compared to 2019 , women in the 1950 s to early 1990 s did experience more discrimination based on gender. However, women always find ways to fight or demand equality in the world of work or everyday life. This fight and resistance defined as gender politics carried out by women. One of the examples of women protest towards male domination is Kate Millet herself, by publishing her book Sexual Politic. Millet divides his sexual politics theory into eight elements; ideology, biology, sociology, class, economics and education, force, anthropology, and psychology. Based on the needs of this study, the author will use 5 out of 8 Millet sexual politic elements. These elements are ideology, biology, class, force, and psychology. Sexual Politic theory 
focuses on the concepts of femininity and masculinity in patriarchal culture, as Millet (2000) explains:

\begin{abstract}
"Sexual politics obtains consent through the "socialization" of both sexes to basic patriarchal polities with regard to temperament, role and status. (...) temperament involves the information of human personality along stereotyped lines of sex category ("masculine" and "feminine"), based on the needs and values of the dominant group and dictated by what its members cherish in themselves and find convenient in subordinates: aggression, intelligence, force and efficacy in the male; passivity, ignorance, docility, "virtue", and ineffectuality in female" (p.26)
\end{abstract}

Based on this statement, the temperament or character of an individual must be in accordance with their respective sexes. The character and role for each gender or sex is constructed socially based on a consensus by the dominant gender group. In this case, men are the dominant group that has the right to control and lead women.

The biological element explains how a person's sex can determine the character that a person must have. Millet (2000) argues that in addition to religious factors, patriarchal culture can grow and develop based on observations of the physical strength possessed by men. On the other hand, Millet explained that basically all humans were women when we were all still in the form of a fetus at a particular stage. But Millet also believes that these gender differences have a significant impact on women and men, as she stated "... because of our social circumstances, male and female are really two cultures and their life experiences are utterly different..." (Millet, 2000, p.31). However, the difference in the physical strength of men and women is undeniable. The physiology of women and men is different and cannot be changed except with medical engineering. The main idea of this element is how a person's physiological conditions can affect his or her character and position in society.

Class, education, and economy have a very close relationship in Millet's theory. Economy and education are two critical elements that can enable a person to have a higher social class or vice versa. Women can be independent and have higher position in society which assume that someone's class status depends on economic, social, and educational conditions (Millet, 2000, p.36). People who have such perspectives are considered ideal societies. In these circumstances, regardless of race and gender, a white farm worker has a lower social stratum than black women who work as doctors. Despite being in an ideal society, men will always tend to play the role of a leader or decision making.

Millet understands "force" as coercion. According to Millet, patriarchal culture is a form of coercion carried out by humans unconsciously. Patriarchal culture is considered to be perfectly internalized in society, one of which is through religion. Millet uses Islam as an example of a religion that practices patriarchy strictly. She argues that "... Islam has implemented the prohibition against illegitimacy or sexual autonomy with a death sentence" (Millet, 2000, p.43). In reality, the death penalty depends on the state or country and not on religion. On the other hand, with the patriarchal culture, Millet argues that the community indirectly accustomed themselves to arbitrary actions by the ruling gender (male). Example, verbal and physical abuse or violence against women considered as a natural act, and something that can be done but must be kept as secrets. Rape is an example of physical violence generally committed by men against women. Rape victims suffer from severe psychological traumas. Apart from the harassment itself, social construction about women also makes women who are rape victims feel ashamed, dirty, and unworthy. Besides feeling ashamed and unworthy, women 
who are victims of rape will tend to feel guilty because they cannot maintain their "holiness." Millet (2000) explains that rape is the most explicit example of sexual politics in which a person has aggression, hatred and a great desire to sexually damage others. Rape also has a huge impact on the physical or psychological victim.

The five elements in Millet's Sexual Politics theory each connected to the Ford and Kavanaugh case. Based on the theory above, the steps taken by Ford to report the attempted rape by Kavanaugh in The Washington Post and congresswoman Eshoo can also be interpreted as gender or sexual politics that she did against Kavanaugh. Both Ford and Kavanaugh are welleducated people. But Kavanaugh has a higher position in the political world than Ford does. In this paper, the author used Braun and Clark thematic analysis method. Braun and Clark (2006) stated that thematic analysis is a method to identify, analyze, and report patterns or themes in the data. Thematic analysis simplifies and sharpens the analysis of research with primary data in the form of interviews or conversational transcripts. The primary data used in this study is a transcript of the hearing of sexual harassment by Kavanaugh against Ford on September 27, 2018. The transcript is divided into two parts, which are opening statement or opening statements from Ford and Kavanaugh. Thematic analysis itself is divided into six stages:

Table 1. Phases of thematic analysis (Braun \& Clark, 2006, p.87)

\begin{tabular}{|c|c|c|}
\hline No. & Phase & Description \\
\hline 1 & $\begin{array}{l}\text { Familiarizing yourself } \\
\text { with your data }\end{array}$ & $\begin{array}{l}\text { Transcribing data (if necessary), reading and } \\
\text { re-reading the data, noting down } \\
\text { initial ideas }\end{array}$ \\
\hline 2 & Generating initial codes & $\begin{array}{l}\text { Coding interesting features of the data in a } \\
\text { systematic fashion across the entire data set, } \\
\text { collating data relevant to each code. }\end{array}$ \\
\hline 3 & Searching for themes & $\begin{array}{l}\text { Collating codes into potential themes, } \\
\text { gathering all data relevant to each } \\
\text { potential theme }\end{array}$ \\
\hline 4 & Reviewing themes & $\begin{array}{l}\text { Checking if the themes work in relation to } \\
\text { the coded extracts (Level 1) and the entire } \\
\text { data set (Level 2), generating a thematic } \\
\text { 'map' of the analysis }\end{array}$ \\
\hline 5 & $\begin{array}{l}\text { Defining and naming } \\
\text { themes }\end{array}$ & $\begin{array}{l}\text { Ongoing analysis to refine the specifics of } \\
\text { each theme, and the overall story the analysis } \\
\text { tells, generating clear definitions and names } \\
\text { for each theme }\end{array}$ \\
\hline 6 & Producing the report & $\begin{array}{l}\text { The final opportunity for analysis. Selection } \\
\text { of vivid, compelling extract examples, final } \\
\text { analysis of selected extracts, relating back of } \\
\text { the analysis to the research question and } \\
\text { literature, producing a scholarly report of the } \\
\text { analysis }\end{array}$ \\
\hline
\end{tabular}

The transcript will be analyzed and dissected by thematic methods and refers to Kate Millet's gender political theory by identifying political power, gender status, and representation of both parties in the hearing of the case. Both opening statements transcripts retrieved from https://www.theguardian.com/us-news/2018/sep/28/christine-blasey-fordsopening-statement-in-full and https://www.nytimes.com/2018/09/26/us/politics/read-brett-kavanaughs-completeopening-statement.html. 


\section{Result and Discussion}

Kavanaugh delivers his opening statement dramatically and emotional. Based on the thematic analysis conducted on his opening statement, there are four major themes that can be extracted; confident, sensitive, defensive, and a good self-portrayal. In a very confident attitude, Kavanaugh starts his opening statement by saying that Ford's best friend, Ms. Keyser, admitted that she doesn't know Kavanaugh nor acknowledge the alleged sexual assault incident. By saying "Her longtime friend, Ms. Keyser, said under penalty of felony that she does not know me and does not believe she ever saw me at a party ever," Kavanaugh wants to convince the audience, especially the senate and jury that Ford's accusation against him is bogus. Kavanaugh wants people to assume that no one would dare to lie under oath. On the other way, it is possible for a witness to cover up their knowledge about some incidents because they are afraid or under certain intimidating circumstances. Another confident attitude that shown in Kavanaugh's speech is when he says, "I know that any kind of investigation, Senate, F.B.I., Montgomery County police, whatever will clear me," This shows that Kavanaugh already knew that the law would support him. This statement can be interpreted as his way on showing his dominance in the US political world. Besides his statements that show confidence and dominance, Kavanaugh is also repeatedly using the word "destroy" (6 times) to describe his family's reputation in the public after the allegation arose. For example, "This has destroyed my family and my good name" and "... a refuted allegation from 36 years ago is enough to destroy a person's life and career," signify how terrible the allegation has affected his family. His description of the difficulties his family face shows that this allegation affects him tremendously, and he also wants to be seen as the victim. Furthermore, the word "destroy" also indicates emotion and how Kavanaugh wants his opponent to be, which is destroyed.

In his defense, he is the victim of the Democratic Party propaganda. Portray himself as a victim and blame Democratic Party is a way of him to defense himself or shifting the blame. Kavanaugh believes that Democrat uses Ford's allegation as the last desperate attempt to overthrow him from the Supreme Court Justice nomination as he firmly stated: "Since my nomination in July, there's been a frenzy on the left to come up with something, anything to block my confirmation. Shortly after I was nominated, the Democratic Senate leader said he would "oppose me with everything he's got." This statement signifies that indeed, the opponent party will do anything at all to hamper Kavanaugh's confirmation. As a member of Republican Party, Kavanaugh is likely to support "pro-life," which oppose to the idea of abortion, which Democratic Party fully supports. If confirmed, Brett Kavanaugh ensures conservative control of the Court, but he will not drive it sharply to the right (DiSanto, 2018). By this statement, Kavanaugh wanted to show and convince that this was all politic maneuver by the left-wing, even though Ford said that she is not affiliated with any political parties. This is also the other word of him to say that Ford is just a tool for Democrat to conduct the propaganda. On the other hand, it is possible that the Democrat use this sexual harassment allegation discourse out of proportion to overthrown Kavanaugh.

After presenting himself as a victim of a political defamation act, Kavanaugh describes how he was always supportive of sexual assault victims and empowering women. He stated: "One of my closest friends to this day is a woman who was sexually abused, and who in the 1990s when we were in our 30s, confided in me about the abuse. Sought my advice. I was one of the only people she consulted". Kavanaugh emphasized that women, or in this case, sexual abuse victim trust him. Therefore it is impossible for him to conduct any type of sexual assault. Furthermore, Kavanaugh once again reminds the audience that he is clean and has an excellent career record by saying: "Throughout that entire time, throughout my 53 years and seven months 
on this Earth until last week, no one ever accused me of any kind of sexual misconduct. No one ever...”.

Kavanaugh continues to maintain his innocence by describing his teenage life as an all American boy (sporty, religious, fun, and lovable). He describes it by explaining his activities based on his calendar that he also used as a diary. This explanation is also used to deny Ford's accusation as he said "If it (the incident) was a weekend, my calendars show that I was out of town almost every weekend night before football training camp started in late August. The only weekend nights that I was in D.C. were Friday, June 4, when I was with my dad at a pro-golf tournament". Besides insinuating that he was not at the place where the alleged incident happens, it also implies that he was very concern about sports events. He stated that he went to church every week when he was an adolescent. This is the kind of image that Kavanaugh wants people to see when he was young. The image of an innocent teenage boy who likes to do sport and go to church and unlikely to do any kind of sexual assault. Kavanaugh also states that Ford's allegation is "radically inconsistent" with his record in his calendar. The usage of the word "radical" is a form of exaggeration in an attempt to point out how he was right, and Ford was wrong. This exaggeration can be interpreted as an expression of frustration or attempt to make his defense believable. Moreover, in this part of his speech, he wants to show how he was morally good and how perfect he was raised by both of his parents. His mother was a lawyer, and he uses his mother's quote "use your common sense" to insinuate that Ford's allegation doesn't make sense and can't be proven.

At the end of his opening statement, he went further to explain that he never had sex or intercourse when he was in high school. On the other hand, being a virgin can't guarantee anyone for not being drunk and unintentionally sexual assaulting anyone. Furthermore, Kavanaugh tries to emphasize his power and support from women by stating, "The committee has a letter from 65 women who knew me in high school. They said I always treated them with dignity and respect". He continues to mention that he is also supported by his friend, who is a feminist. These statements indicate that Kavanaugh wants to build an image that a person who has been supporting and supported by women is unlikely to do such a crime. At his opening statement's closing Kavanaugh again stated that "My family and I intend no ill will toward Dr. Ford or her family," this insinuate that it is not Ford that Kavanaugh wants to blame, but the Democratic Party is the mastermind of all this commotions.

Inversely to Kavanaugh's opening statement, Ford's opening statement was delivered less emotional. Based on the thematic analysis that was conducted on her opening statements, there are three major themes that can be extracted; negativity, struggle, and sexual assault. Negativity element describes the fear and worries that Ford had due to the allegation and the hearing. As Ford mentioned at the beginning of her statement, "I am here today not because I want to be. I am terrified," shows that she acknowledge her position in the hearing is vulnerable. Kavanaugh, with his dominance in the US political world, indirectly affects Ford's confidence. At the beginning of her opening statement, Ford explains that she doesn't remember the details about the gathering, but she only remembers the detail of the assault as she stated "I do not remember all of the details of how that gathering came together... But the details that - about that night, that bring me here today are the ones I will never forget". The incident happened in 1982, and it will difficult even for the victim of sexual assault to remember all the details of the event.

In her opening statement, Ford doesn't try to portray herself as an all American sweetheart like Kavanaugh does. Instead, in retelling the allege incident Ford admits that she was underage who drink alcohol. Her drinking alcohol when she was underage had also become one of the reasons why she didn't report the incident immediately. She argues that she will be blamed for 
the occurrence of the incident. There are some stereotype regarding women who drinks alcohol. One of the stereotypes is that women who drink alcohol are frequently perceived as being more sexually available and sexually promiscuous than women who do not drink alcohol (Abbey, 2002, p.121). Beside perceive as promiscuous, women who drink alcohol is considered as a signal for men for some sexual advances (Abbey, 2002). These factors cause Ford's delayed report on the sexual assault that is allegedly conducted by Kavanaugh 36 years ago. This also shows that even then Ford realize that going against Kavanaugh in that moment of time will be difficult, since he was a boy who came from a prominent family and known very well by the society. There are many factors as to why many sexual assault victims delay or don't report the incident at all. Rennison (2002) explains that $63 \%$ of sexual assault incidents were never reported to the police. However, there are also reports of sexual assault that were fabricated or falsified by the victim's alleged party against a variety of motives such as revenge and defamation. According to Lisak et al. (2010), Ford's actions fall into two of four categories of false allegation reports: "... A case in which the victim appears to make inconsistent statements..., a case in which a victim makes a delayed report of the incident..."(p.1320).

The negative or pessimist feelings that she has continue to the day of the hearing as she stated: "Persons painted him as a champion of women's rights and empowerment. And I believed that if I came forward, my single voice would be drowned out by a chorus of powerful supporters". By expressing that she acknowledges how powerless she is compared with Kavanaugh either in gender and political world. In the other hand, this acknowledgment can be interpreted as way of Ford to gain sympathy from the audience. It shows that even though she is powerless compare to Kavanaugh and knows that she won't be able to defeat him, she keeps on trying and giving the image as a survivor rather than a victim of a sex crime. Ford recounts the incident as a very traumatic event. According to her statement, Kavanaugh forced and pushed her onto the bed and tried to rape her by groping her. Moreover, she believed that at that time, Kavanaugh would accidentally kill her. Contrary to Ford, Kavanaugh denied he had been drinking to the point where he blacks out. Domination by men towards women can be interpreted as a manifest of the ideology of masculinity and femininity that is constructed in society. The extreme form of domination is rape. Tolman (2015) explains that gender hierarchy in society often used by each gender to politicized their objectives. There is no crime that is so full of controversy, which can lead to debate in the politics of gender and sexuality than sexual crime cases (Lisak et al., 2010). In general, this case is a "he said - she said" case where there is no evidence that can deny or confirm any accusations.

Behind all the negative feelings she has, she was adamant about giving her testimony in the hearing. Her motivation to come forward is to show the people of the United States what kind of person Kavanaugh, the supreme court judge nominee was. She firmly stated that her coming forward was not as any politic parties partisan. At first, she wanted her identity to be anonymous when she reported the incident to congresswomen Anna Esho, Senator Feinstein, and The Washington Post. She kept her identity out of the public eyes because she knew that it is almost like a suicide mission to go against a very powerful person like Kavanaugh, especially in his time of nomination. However, she also stated that: "... do I share the facts with the Senate and put myself and my family in the public spotlight, or do I preserve our privacy and allow the Senate to make its decision without knowing the full truth of his past behaviors?" This statement shows that Ford realizes, if she doesn't come out and tell the story herself, the media can go wild and potentially write a false story. Since Ford went public about the allegation, she too, like Kavanaugh, experience some threat and pressure from a lot of people. Ford didn't use emotional words like "destroy" as Kavanaugh did to describe the condition of his family. Ford stated that "These messages, while far fewer than the expressions of support, have been 
terrifying and have rocked me to my core". This statement express more fear than emotion, and the word "terrifying" also indicate helplessness.

At the end of her opening statement, Ford was again telling the audience that she was not affiliated with any political parties as she stated, "I have been accused of acting out of partisan political motives. Those who say that do not know me. I'm an independent person, and I am no one's pawn". However, it can't be denied that Ford's allegation has become an advantage for Democrats to defame Kavanaugh. Beside coincided with Kavanaugh's nomination, the allegation also arose coincided with MeToo movements, making it more difficult for Kavanaugh to defend himself. Despite all the support Ford get, eventually the allegation is dismissed due to Kavanaugh's confirmation to the Supreme Court Justice. Even though this can be interpreted that Kavanaugh's power in the political world can dominate the allegation, the fact that Ford has not any forensic evidence is one of the reasons why the allegation was dismissed.

\section{Conclusion}

Kavanaugh - Ford's sexual allegation case is a good example of how power in the political world can win over the voice of the majority (people's support for Ford). On the other hand, even though armed with evidence and support from the feminists and democrats, Ford still can't hamper the confirmation of Kavanaugh. It is not only because Kavanaugh presenting himself as a good American man in the opening statement that set him free from the allegation. The lack of evidence Ford has is too weak to be used to bring Kavanaugh into the justice system. The discourse of sexual harassment, which was the national spotlight at that time, became one of the weapons that Democrat to overthrown Kavanaugh by Ford's allegation. Kavanaugh chose to present all of his dominance in the political world and his all American boy image to defend himself, but Ford tends to admit to her wrongdoing such as drinking when she was underage. It is a win-lose case for both Kavanaugh and Ford. Both of them have their reputation destroyed, and none of them got any compensation out of the allegation.

\section{References}

[1] Abbey, A. (2002). Alcohol-Related Sexual Assault: A Common Problem among College Students. Department of Community Medicine, Wayne State University, 118-128.

[2] Brown, E. (2018, September 17). Investigations: California Professor, writer of confidential Brett Kavanaugh Letter, Speaks Out About Her Allegation of Sexual Assault. Retrieved from The Washington Post: https://beta.washingtonpost.com/investigations/california-professor-writer-ofconfidential-brett-kavanaugh-letter-speaks-out-about-her-allegation-of-sexualassault/2018/09/16/46982194-b846-11e8-94eb-3bd52dfe917b_story.html

[3] Catherine Hill, E. S. (2005). Drawing the Line: Sexual Harassment on Campus. American Association of University Women Educational Foundation.

[4] Conroy, N. E. (2013). Rethinking Adolescent Peer Sexual Harassment: Contribution of Feminist Theory. Journal of School Violence, 340-356.

[5] David Lisak, L. G. (2010). False Allegations of Sexual Assault: An Analysis of Ten Years of Reported Case. SAGE.

[6] Deborah L. Tolman, B. R. (2015). "That's Just How It Is": A Gendered Analysis of Masculinity and Feminity Ideologies In Adolescent Girls' and Boys' Heterosexual Relationships. Journal of Adolescent Research, 1-29. 
[7] DiSanto, J. (2018, July 10). Perspectives on Supreme Court nominee Brett Kavanaugh. Retrieved from Penn Today: https://penntoday.upenn.edu/news/perspectives-supreme-court-nomineebrett-kavanaugh

[8] Fortin, J. (2018, Oktober 10). \#MeToo Leaders Thank Christine Blasey Ford: 'Your Sacrifice Was Not Made in Vain.' Retrieved from The New York Times: https://www.nytimes.com/2018/10/10/us/me-too-letter-dr-ford.html

[9] Heig, D. (2004). The Inexorable Rise of Gender and the Decline of Sex: Social Change in Academic Titles, 1945-2001. Sexual Behavior, 87-96.

[10] Long, C. (2017, December 4). The Secret of Sexual Assault in Schools. Retrieved from neaToday: http://neatoday.org/2017/12/04/sexual-assault-in-schools/

[11] Millet, K. (2000). Sexual Politic. Chicago: University of Illinois Press.

[12] Jeffreys, S. (2010). Kate Millett's Sexual Politics: 40 years on. Elsevier, 76-84.

[13] Rennison, C. M. (2002, August). Rape and Sexual Assault: Reporting to Police and Medical Attention, 1992-2000. Retrieved from U.S Departement of Justice: https://bjs.gov/content/pub/pdf/rsarp00.pdf

[14] The Guardian. (2018, September 28). Retrieved from The Guardian: https://www.theguardian.com/us-news/2018/sep/28/christine-blasey-fords-opening-statement-in-full [15] The New York Times. (2018, September 26). Retrieved from The New York Times: https://www.nytimes.com/2018/09/26/us/politics/read-brett-kavanaughs-complete-openingstatement.html

[16] Totenberg, N. (2018, December 18). Federal Panel Of Judges Dismisses All 83 Ethics Complaints Against Brett Kavanaugh. Retrieved from National Public Radio: https://www.npr.org/2018/12/18/678004085/federal-panel-of-judges-dismiss-all-83-ethicscomplaints-against-brett-kavanaugh

[17] Triplett, M. R. (2012). Sexual Assault on College Campuses: Seeking the Appropriate Balance Between Due Process and Victim Protection. Duke University School of Law, 487-527.

[18] Virginia Braun, V. C. (2006). Using thematic analysis in Psychology. Edward Arnold, 77-101

[19] Zhou, L. (2018, September 27). Christine Blasey Ford shows the lengths women have to go to be believed. Retrieved from Vox: https://www.vox.com/policy-andpolitics/2018/9/27/17880490/supreme-court-nominee-christine-blasey-ford-kavanaugh 